\title{
Measurement of estradiol-induced wheel running with brief time samples
}

\author{
JAMES M. KING and VERNE C. COX \\ University of Texas, Arlington, Texas 76019
}

Brief 1- and 2-h samples of running wheel activity were shown to be sensitive to the facilitative effects of estradiol on general activity.

Twenty-four-hour measures are typically employed to determine the effects of food deprivation (Finger, 1951; Jakubczak, 1973; Richter, 1922), estrus (Finger, 1969; Wang, 1923), and other variables on wheel running activity. A number of investigators have found that much briefer samples of wheel running can be employed to detect hunger effects on activity (Duda \& Bolles, 1963; Finger, Reid, \& Weasner, 1957). Brief time samples of wheel running, when they can be used, greatly increase the efficiency of activity wheels as data collection devices. There is no existing information regarding the detectability of estrogen-related wheel running activity with brief time samples. In other behavioral situations, direct observations have revealed estrusrelated activity in periods of $5 \mathrm{~min}$ or less (Burke \& Broadhurst, 1966; Guttman, Lieblick, \& Gross, 1975). With regard to wheel running activity, Jennings (1969) has reported detection of estrus-related activity with 12-h samples. We were interested in determining if the effects of estradiol on wheel running activity (Mook, Kenney, Roberts, Nussbaum, \& Rodier, 1972; Young \& Fish, 1945) could be detected with brief samples of wheel running activity. To explore this possibility, we examined the effects of estradiol injections in ovariectomized rats on 1-and 2-h samples of wheel running activity.

\section{EXPERIMENT I}

\section{Method}

Subjects. Fourteen experimentally naive female Holtzman albino rats, which weighed approximately $230 \mathrm{~g}$ at the start of the experiment, were employed. They were housed in individual cages, with Purina Lab Chow and water continuously available in the home cage. A 16-h dark, 8-h light, reversed L-D cycle was maintained in the animal quarters, and the temperature was maintained at approximately $22^{\circ} \mathrm{C}$. The subjects were given at least 10 days to adapt to the L-D cycle.

Procedure. The subjects ran in standard Wahmann LC-34 activity wheels for $2 \mathrm{~h}$ /day during the dark portion of the L-D cycle. Each wheel was adjusted to within $10 \%$ of the mean friction by the method of Lacey (1944). Activity was recorded on cumulating counters attached to each wheel. Neither food nor water was available in the wheels, and the running room was dimly illuminated with a $40-\mathrm{W}$ red light. The animals were weighed at the conclusion of each day's run. After 14 days of baseline data had been collected, the subjects were anesthetized with an intraperitoneal injection of Chloropent and bilaterally ovariectomized. The flank incisions were closed with silk sutures and wound clips. Beginning on the day following surgery, half of the animals were given daily subcutaneous injections of 3.0 micrograms of estradiol benzoate (EB) in .1 ml sesame oil, while the control subjects were injected with a comparable volume of oil. Activity and body weight were recorded for 12 additional days, beginning on the second day following surgery. All activity scores were converted to percentages of the mean activity score for the last 4 baseline days; body weight scores were converted to percentages of the body weight on the last baseline day. Activity and body weight scores were analyzed as 4-day block means.

\section{Results}

The mean baseline activity was 595 turns/h for the hormone treated group and 530 turns/h for the oil controls. The results are contained in Table 1. A repeated-measures analysis of variance (ANOVA) applied to the activity data revealed a significant Hormone effect $[F(1,12)=9.76, p<.01]$, indicating that the hormone treated subjects were more active than the oil controls. The significant Blocks effect $[\mathrm{F}(2,24)=5.40, \mathrm{p}<.025]$ reflected recovery from surgery, while the significant Hormone by Blocks interaction $[F(2,24)=5.12$, $p<.025$ ] reflected the increasing activity of the hormone treated subjects. A repeated-measure ANOVA applied to the body weight data revealed a significant Hormone effect $[F(1,12)=59.60, p<.001]$, indicating that the EB prevented postovariectomy weight gain, while both the significant Blocks effect $[F(2,24)=$ $143.63, \mathrm{p}<.001]$ and Hormone by Blocks interaction $[F(2,24=66.51, p<.001]$ reflected the increased rate

Table 1

Mean Activity and Body Weight: Percentage of Baseline (4-Day Blocks)

\begin{tabular}{lccr}
\hline & 1 & 2 & 3 \\
\hline & \multicolumn{3}{c}{ Activity } \\
$3.0 \mu \mathrm{g} \mathrm{EB} /$ Day & 92.5 & 120.7 & 125.7 \\
Oil & 69.9 & 75.3 & 67.3 \\
& \multicolumn{3}{c}{ Body Weight } \\
$3.0 \mu \mathrm{g} \mathrm{EB} /$ Day & 96.7 & 97.1 & 98.7 \\
Oil & 100.9 & 105.8 & 111.7 \\
\hline
\end{tabular}


of weight gain of the oil treated group. Experiment II was designed to replicate and extend the present findings.

\section{EXPERIMENT II}

\section{Method}

Subjects. Sixteen experimentally naive female Holtzman albino rats, which weighed approximately $280 \mathrm{~g}$ at the start of the experiment, were employed. Housing conditions were as described in Experiment I. The subjects were given at least 10 days to adapt to the L-D cycle.

Procedure. The activity wheels were as described in Experiment I. Subjects were run for $1 \mathrm{~h} /$ day during the dark portion of the L-D cycle. Powdered Purina Lab Chow and water were available in the activity wheels. After 11 days of baseline activity and body weight data had been collected, surgery was performed as described in Experiment I. Beginning on the day following surgery, the eight hormone subjects received daily subcutaneous injections of 1.5 micrograms of EB in $.1 \mathrm{ml}$ of sesame oil, while controls were injected with oil alone. Activity and body weight data were collected for 12 days, beginning on the day following surgery. Data analysis was conducted as described in Experiment I.

\section{Results}

The mean baseline activity was 352 turns/h for the hormone treated subjects and 359 turns/h for the oil controls. The results are contained in Table 2 . A repeated-measures ANOVA applied to the activity data revealed a significant Hormone effect $[\mathrm{F}(1,14)=10.96$, $\mathrm{p}<.01]$, reflecting the greater activity of the hormone treated subjects, and a significant Blocks effect $[F(2,28)=25.28, p<.001]$, indicating recovery from surgery during the first block. The Hormone by Blocks interaction was not significant. A repeated-measures ANOVA applied to the body weight data revealed a significant Hormone effect $[F(1,14)=24.01, p<.001]$, indicating that the EB prevented the weight gain which follows ovariectomy, while both the significant Blocks effect $[\mathrm{F}(2,28)=38.64, \mathrm{p}<.001]$ and Hormone by Blocks interaction $[\mathrm{F}(2,28)=7.07, \mathrm{p}<.005]$ reflected the increased rate of weight gain of the oil treated group.

\section{DISCUSSION}

These experiments, which employed doses of EB in the range commonly employed for the maintenance of normal body weight and food intake (King \& Cox, 1973; Tarttelin \& Gorski,

Table 2

Mean Activity and Body Weight: Percentage of Baseline (4-Day Blocks)

\begin{tabular}{lccc}
\hline & 1 & 2 & 3 \\
\hline & \multicolumn{3}{c}{ Activity } \\
1.5 $\mu \mathrm{g} \mathrm{EB} /$ Day & 59.4 & 101.1 & 96.0 \\
Oil & 36.6 & 61.9 & 54.6 \\
& \multicolumn{3}{c}{ Body Weight } \\
1.5 $\mu \mathrm{g} \mathrm{EB/Day}$ & 97.0 & 98.3 & 100.4 \\
Oil & 98.5 & 102.7 & 106.9 \\
\hline
\end{tabular}

1973), female sexual behavior (Davidson, Smith, Rogers, \& Block, 1968), and locomotor activity (Gerall, Napoli, \& Cooper, 1973; Mook et al., 1972; Stern \& Murphy, 1972) following ovariectomy, clearly indicate that brief samples of wheel running activity are sensitive to the facilitative effects of estradiol. The present activity measuring techniques will allow more efficient use of running wheels for many experiments involving the estrogenic induction of activity.

\section{REFERENCES}

Burke, A. W., \& Broadhurst, P. L. Behavioral correlates of the estrous cycle in the rat. Nature, 1966, 209, 223-224.

Davidson, J. M., Smith, E. R., Rodgers, C. H., \& Block, G. J. Relative thresholds of behavioral and somatic responses to estrogen. Physiology and Behavior, 1968, 3, 227-229.

DudA, J. J., \& Bolles, R. C. Effects of prior deprivation, current deprivation, and weight loss on the activity of the hungry rat. Journal of Comparative and Physiological Psychology, 1963, 56, 569-571.

FINGER, F. W. The effect of food deprivation and subsequent satiation upon general activity of the rat. Journal of Comparative and Physiological Psychology, 1951, 44, 557-564.

Finger, F. W. Estrus and general activity in the rat. Journal of Comparative and Physiological Psychology, 1969, 68. 461-466.

Finger, F. W., Reid, L. S., \& Weasner, M. H. The effect of reinforcement upon activity during cyclic food deprivation. Journal of Comparative and Physiological Psychology. 1957, 50, 495-498.

Gerall, A. A., Napoli, A. M., \& Cooper, U. C. Daily and hourly estrous running in intact, spayed, and estrone implanted rats. Physiology and Behavior. 1973, 10, 225-229.

Guttman, R., Lieblick, I., \& Gross, R. Behavioral correlates of the estrous cycle stages in laboratory mice. Behavioral Biology, 1975, 13, 127-132.

Jukubczak, L. F. Frequency, duration, and speed of wheel running of rats as a function of age and starvation. Physiological Psychology, 1973, 1. 13-16.

JENNINGS, W. A. Estrous variations in the total behavior output of the female rat. American Zoologist, 1969, 9. 1067.

King, J. M., \& Cox, V. C. The effects of estrogens on food intake and body weight following ventromedial hypothalamic lesions. Physiological Psychology. 1973, 1, 261-264.

LACEY, O. L. A revised procedure for the calibration of the activity wheel. American Journal of Psychology. 1944. 57, 412-420.

Mook, D. G., Kenney, N. J., Roberts, S., Nussbaum, A. I., \& Rodier, W. I. Ovarian-adrenal interactions in regulation of body weight by female rats. Journal of Comparative and Physiological Psychology, 1972, 81, 198-211.

Richter, C. P. A behavioristic study of the activity of the rat. Comparative Psychology Monographs, 1922, 1, 1-55.

Stern, J. J., \& MurPhy, M. The effects of thyroxine and estrodiol benzoate on wheel running activity in female rats. Physiology and Behavior, 1972, 9, 79-82.

STERN, J. J., \& Zwick, G. Hormonal control of spontaneous activity during the estrous cycle of the rat. Psychological Reports, 1972, 30, 483-488.

TARTtelin, M. F., \& Gorski, R. A. The effects of ovarian steroids on food and water intake and body weight in the female rat. Acta Endocrinologica, 1973, 72, 551-568.

WANG, G. H. The relation between spontaneous activity and oestrous cycle in the white rat. Comparative Psychology Monographs, 1923, 2, 1-27.

Young, W. C., \& Fish, W. R. The ovarian hormones and spontaneous running activity in the female rat. Endocrinology. 1945, 36, 181-189.

(Received for publication April 7, 1976.) 